\title{
Embodied Cognition and Perception: Dewey, Science and Skepticism
}

\author{
Matthew Crippen \\ Department of Philosophy, American University in Cairo, \\ AUC Avenue, P.o. Box 74, Cairo 11835, Egypt \\ crippenm@aucegypt.edu \\ Proof (working draft): Please cite original!!!!
}

\begin{abstract}
This article examines how Modern theories of mind remain even in some materialistic and hence ontologically anti-dualistic views; and shows how Dewey, anticipating Merleau-Ponty and $4 \mathrm{E}$ cognitive scientists, repudiates these theories. Throughout I place Dewey's thought in the context of scientific inquiry, both recent and historical and including the cognitive as well as traditional sciences; and I show how he incorporated sciences of his day into his thought, while also anticipating enactive cognitive science. While emphasizing Dewey's continued relevance, my main goal is to show how his scientifically informed account of perception and cognition combats skepticism propagated by certain scientific visions, exacerbated by commonplace notions about mind, that jointly suggest that human beings lack genuine access to reality.
\end{abstract}

\section{Keywords}

Dewey - cognitive science - embodied mind - enactivism - history of science Merleau-Ponty - pragmatism - skepticism

\section{Introduction}

Despite many competing theories of mind emerging since the beginning of the Modern era, most agree on basic points: that there are inner and outer worlds, and perception and cognition function to represent what the organism cannot

* I would like to thank Tibor Solymosi for his helpful feedback on early drafts of this paper. 
access directly. This generates an epistemological dualism of inner versus outer, which leads immediately to skepticism insofar as the world of representation is almost by definition one of appearance. Skepticism has accordingly been a defining issue of the Modern and Post-Modern era.

I do not attempt anything so audacious as overcoming problems with which Descartes and other Moderns left us, much less tritely rejecting them. Rather, I focus on how Modern ideas about mind, which are not necessarily wholly wrong, but too narrowly focused on what occurs inside the head, along with accompanying epistemological dualisms, remain even in some materialistic and hence ontologically anti-dualistic outlooks. I discuss how John Dewey, anticipating Maurice Merleau-Ponty and $4 \mathrm{E}$ cognitive scientists, lessened the divide between inner and outer by suggesting extra-neural mechanisms are involved in perception and cognition; and how, by showing active bodies can perform integrative operations traditionally attributed to "inner" mechanisms, he moved away from mind-body dualism and contemporary variants such as brain-body dualism. Throughout I locate Dewey's thought in the context of scientific inquiry, both recent and historical and taken broadly to include the cognitive as well as more traditional sciences; and I consider how he incorporated the sciences of his day into his thought, while also anticipating recent developments in enactive cognitive science.

While I hope to thereby emphasize the continued relevance of Dewey, whom a number of scholars regard as prescient (see Schulkin, 2004; Rockwell, 2005; Solymosi and Shook, 2013), my primary aim is to show how Dewey's scientifically informed account of perception and cognition helps overcome skepticism propagated by certain scientific visions, exacerbated by Modern era ideas about mind, that together suggest that the individual subject lacks genuine access to reality. Dewey, for example, combated the sort of skepticism that holds color perception merely gives us a representation and not genuine qualities of things; or that we are deceived when we perceive things as solid since they are mostly made of space on an atomic level. Dewey saw such judgments as arising from a failure to recognize that determinable aspects of reality are products of relationships; and when registered by us, whether through perceptual faculties or scientific instruments, they are consequences of our conduct, and accordingly should be judged from the standpoint of specific action-scenarios generating them. For reasons to be discussed, this suggests there is often no genuine conflict between scientific views and everyday experiences, while simultaneously offering rigorous standards for weeding out ill-conceived ideas. It also supplies epistemic basis for both our experiences and scientific knowledge since both are products of changes occurring in our surroundings, as opposed to just our heads. 
Models of mind and human physiology often reflect the scientific and technological zeitgeist of the times in which they are advanced. As John Daugman (2001) noted:

Theorizing about the brain and mind has been especially susceptible to sporadic reformulation in terms of the technological experience of the day. For example, the water technology of antiquity (fountains, pumps, water clocks) underlies ... the Greek pneumatic concept of soul (pneuma) and the Roman physician Galen's theory of the four humours; the clockwork mechanisms proliferating during the Enlightenment are ticking with seminal influence inside La Mettrie's L'Homme Machine (1784); Victorian pressurized steam engines and hydraulic machines are churning underneath Freud's hydraulic construction of the unconscious and its libidinal economy; the arrival of the telegraph provided Helmholtz with his basic neural metaphor, as did the relay circuits and solenoids for Hebb's theory of memory; and so on (24; see also Schulkin, 2016, 8).

A dominant metaphor from the second half of the $20^{\text {th }}$ century onward, though one under pressure in recent decades, is the computer. Though the technology is fairly new, a number of tenets in this metaphor, particularly in popularized versions, are about 500 years old.

The cognitive scientist Donald Hoffman (2009, 2011; and Prakash 2014) supplies a recent example of the metaphor by comparing perception to MS Windows and comparable programs that help us accomplish tasks while unaware of the physical processes that run computers. Such programs guide users' operations of the mouse, triggering complicated changes "inside the computer, completely hidden from the user. Forcing the user to see the true causal chain would be an impediment, not a help" (Hoffman and Prakash, 2014, n.p.) because reports of voltage levels, magnetic fields and so on would be paralyzing and also irrelevant in most cases. For such reasons, interfaces not only fail to provide the truth; they keep it from us. According to Hoffman (2011), "[p]erceived space and time are simply the desktop of the perceptual interface of Homo sapiens. Objects, with their colors, shapes, textures, and motions, are simply the icons of our space-time desktop" (12). Because perceptual systems cost organisms valuable calories, "natural selection pressures perception to be quick and cheap" (11). As with computer interfaces, getting veridical percepts of the environment "is too expensive in time and energy. It is also not usually relevant, since utility, not truth," is what matters (11). The reason, therefore, 
that we rarely step in front of busses and do other reckless things "is the same reason one would not carelessly drag a file icon to the trashcan." While "the shape and color of the file icon do not resemble anything about the true file," dragging "the icon to the trash ... [could cost] many hours of work. We know not to take the icons literally. ... But we also know to take [them] seriously" (12). So similarly with perception. We take it seriously even though it is not veridical, at least this is what Hoffman's theory contends.

Richard Dawkins provides another example of mind as computer as well as the skepticism-inducing scientism Dewey was trying to escape. While something of a caricature, even though Dawkins was in earnest, it provides an illustrative case precisely because it is a caricature vis-à-vis mind as representing machine that typifies Modern era views that survive today. In his 2006 The God Delusion, Dawkins wrote: "The human brain runs first-class simulation software," explaining by way of example that “[o]ur eyes don't present to our brains a faithful photograph [or movie] of what is out there" (88). Instead, [o] ur brains construct a continuously updated model: updated by coded pulses chattering along the optic nerve" (88-89). Repeatedly emphasizing a digital, pulsing on-off picture, Dawkins supplied other examples of how the brain simulates experiences of what is not actually occurring in the world, for instance, describing separate harmonics that the brain synthesizes into the brassy or reedy timbres of trumpets or clarinets. His account of cognition mirrors his conception of perception. "Each of us builds, inside our head, a model of the world in which we find ourselves" (361), he said, adding that we are constrained by our evolutionary past. Consequently, the challenge is to move beyond "the minimal model of the world [that] our ancestors needed in order to survive in it" (361). Because our brains are "on-board computers, evolved to help us survive in a world ... where the objects that mattered to our survival were neither very large nor very small" and "where things either stood still or moved slowly compared with the speed of light" (367), we struggle to imagine vast cosmic sizes or quantum strangeness, to picture atoms or electron zones and so on.

While arguing that people are mostly duped in their everyday perceptions and thoughts, Dawkins (2006) nonetheless insisted that something approaching accurate representational knowledge is possible. Here too he invoked the concept of "simulation software." Only in this instance he explained the brain can construct tolerably accurate models of the universe because scientific methodology, technological instruments and mathematics widen the slit of what he calls our "mental burka," for example, allowing us to detect and understand portions of the electromagnetic spectrum outside the visual range (see 361-374). Human brains, on this view, "turn out to be powerful enough to accommodate a much richer world model than the mediocre utilitarian one that 
our ancestors needed in order to survive" $(361-362)$. We can therewith come to understand the universe through what he called "a model-building enterprise" (361), and by means of this realize we are vastly mistaken in our everyday experience of the world. Again, Dawkins's account of mind is somewhat superficial and does not address the nuances and differences between, say, Hilary Putman, Jerry Fodor and Fred Dretske. Nevertheless it reflects academic positions that have gained traction, while also mirrored in popular views, whether conveyed in movies such as The Matrix (1999) or delivered by psychology and philosophy professors presenting the mind or brain as a world-representing machine; and despite being framed in the language of neuro- and computer science, the account offered by Dawkins, like that of Hoffman, parallels early Modern outlooks.

Dawkins and Hoffman's views do so, most obviously, by emphasizing an inner-outer divide. While many take this divide for granted today, it has not always been so readily accepted. Hubert Dreyfus (2003), for example, observed that the Homeric Greeks regarded inner experience as an exceptional phenomenon, as evidenced by the fact that "Homer considered it one of Odysseus's cleverest tricks that he could cry inwardly while his eyes remained [dry]," and noted further that there are few if any other references to inner experience in Homer's works. Along similar lines, Dewey (1925) claimed that "inner experience" was a Modern era discovery (172), whereas to the ancient Greeks, "experience was the outcome of accumulation of practical acts, sufferings and perception gradually built up into the skill of the carpenter, shoemaker, pilot, farmer, general, and politician." Having experience meant being experienced or skilled, so that " $t]$ here was nothing merely personal or subjective about it" (230; also see Crippen, 2014, 2016a, 2016b). This was the model that Dewey adopted, anticipating enactivists such as Kevin O'Regan and Alva Noë, who, in their landmark 2001 article, proposed that perception is "the activity of exploring the environment in ways mediated by knowledge of the relevant sensorimotor contingencies" (943), so that "seeing is a way of acting" (939). On this view, which is also Dewey's, a great deal of our perception occurs, to borrow from the title of Noë's 2009 book, "out of our heads."

A second and related way in which Dawkins's and Hoffman's stances resemble early Modern views is that, while materialistic and therefore antagonistic towards mind-body dualism, they suggest we live in a world of mental appearance and therewith retain epistemological dualism. The framing of Dawkins's and Hoffman's examples, despite occasional claims to the contrary, also assumes there is more or less one reality; and, relatedly, that there is one truth on a given matter-something upon which even Descartes and Hume agreed despite differences elsewhere. Both accounts consequently assume there is a 
world as it really is, and then our representations of it, which, by virtue of being representations, only give us the world as it appears.

\section{Ilternative Views}

Anticipating the kind of dualisms that often follow from many contemporary materialist accounts, Dewey (1916), roughly a century ago, wrote:

The advance of physiology and the psychology associated with it have shown the connection of mental activity with that of the nervous system. Too often recognition of connection has stopped short at this point; the older dualism of soul and body has been replaced by that of the brain and the rest of the body (361).

Dewey of course recognized the importance of the brain, but he also advanced the view, as Merleau-Ponty (1945) would put it some years later, that the "body is not a collection of adjacent organs, but a synergic system, all the functions of which are exercised and linked together in the general action of being in the world" (272). Dewey, along with Merleau-Ponty, maintained we only perceive and cognize through bodily sensitivities and capacities coordinating into joint action. This includes real-time coordinations and also past ones through which we acquire habits that help us deal with things and indeed characterize how we perceive them; and, critically, capacities and sensitivities coordinate not on their own, but by synchronizing around environmental contours-points taken up in detail later. Dewey (1916), to be sure, granted that the nervous system is crucial, but added that it

is only a specialized mechanism for keeping all bodily activities working together. Instead of being isolated from them, as an organ of knowing from organs of motor response, it is the organ by which they interact responsively with one another. The brain is essentially an organ for effecting the reciprocal adjustment to each other of the stimuli received from the environment and responses directed upon it (361).

Crucially, moreover, "the adjusting is reciprocal; the brain not only enables organic activity to be brought to bear upon any object of the environment in response to a sensory stimulation, but this response also determines what the next stimulus will be" (361-362). As O'Regan and Noë (2001) observed, for example, "seeing involves testing the changes that occur through eye, body, and 
attention movements" (947), and the brain plays a role in these adjustments and therewith in determining what stimuli are received.

Dewey was not alone in emphasizing the brain since William James and numerous others in his day also did. Even Dewey's emphasis on extra-neural mechanisms was emblematic of his time, despite also being forward thinking, insofar as others under the influence of Darwinism and the biological sciences were hinting at comparable positions. Francis Galton, in 1883, discussed an "incipient motor sense, not of the eyeballs only but of the muscles generally," which he related to mental imagery (61). Edward Titchener (1909) similarly proposed that " $[\mathrm{m}]$ eaning is, originally, kinaesthesis; the organism faces the situation by some bodily attitude" (176). Some years later, Margaret Floy Washburn, in her 1916 Movement and Mental Imagery: Outlines of a Motor Theory of the Complexer Mental Processes, positted that "the whole of the inner life is correlated with and de-pendent upon bodily movement" (xiii). ${ }^{1}$

That Dewey and his contempories proposed such ideas is remarkable in light of recent neuroscientific work, for as Jay Schulkin (2004) observed:

we now know that the head ganglia of motor control and the organization of movement and habit - the basal ganglia — is linked to a wide array of cognitive functions. They include language production, the paradigmatic example of a cognitive system [...]. For example, syntax production for regular verbs $[\ldots]$, the prediction of a probabilistic event $[\ldots]$, the organization of specific movements [...], and the appraisal of rewards ... all involve the basal ganglia (18-19).

Schulkin also connected the late 19th and early 2oth century emphasis on bodily activity to Darwinism (8), a point repeated by Kristof Nyiri (2014, 136, fn. 57). The theory stresses adaptation, something emphatically related to the body but also intelligence, thus providing a link between motoricity and mind. Of Dewey, Schulkin specifically noted that he

attempted to modify the idea of the reflex arc inherited from Descartes by building cognitive systems right into the reflex responses. This was a prescient orientation, for we have recognized that elementary motor control is embedded in cognitive systems that organize the structure of action (18; also see Rockwell, 2014).

1 Kristof Nyiri quoted the above-cited Galton, Titchener and Washburn passages in his plenary talk, Towards a Theory of Common-Sense Realism, presented at Visual Learning: Trust, Time, Tradition, Budapest University of Technology and Economics, November 13, 2015. 
In fact, it was more prescient than even this, since embodied cognitive scientists and some phenomenologists have recognized the reverse, namely, that cognitive systems are embedded in motor activity, a point to which I now turn.

\section{Dewey's Embodied Theory of Perception and Recent Views}

On Dewey's account, perception involves an outward giving and giving into, or, as he put it, "an act of the going-out ... in order to receive" (1934, 53). When reaching out to receive a wood carving, our fingers wrap around it, giving into its form. The carving, to borrow from Merleau-Ponty, "utilizes the time occupied by our tactile exploration or modulates the movement of our hand" $(1945,315)$, thereby patterning a perceptual experience. This idea, which has roots in many places, including C.S. Peirce's $(1878,293)$ pragmatic maxim, is repeated by contemporary enactivists. For instance Erik Myin and Jan Degenaar (2014) observed that "tactile feelings of hardness or softness are determined by particular patterns of experiences one has when engaging in such activities as squishing a sponge or pushing a brick wall" (91). Using an example of a bottle, Noë (2004) made a similar point, albeit one emphasizing engagement through understanding to an extent that makes radical enactivists such as Daniel Hutto and Myin (2013) uncomfortable. "The bottle as a whole is present to you," wrote Noë, "not because you now represent the sense of having an internal model of it, but in the sense that you now understand the way in which it structures and controls your movements, and so your sensory stimulation." Thus "[ $\mathrm{t}]$ he content of your tactile experience is enacted by your exploratory movements (73).

Interestingly, the views advanced by Dewey and later by enactivists both affirm and denies tenets of competing empiricist and rationalist schools. That entities shape the hand's actions and therewith experience does not mean the hand and more generally the human subject yield like clay, for they are constrained by their capacities and possibilities of action. So far this sounds like rationalism made bodily; notice, however, that actions in the world, acquired habits and skills, which Dewey and enactivists link to other perceptual modes such as vision, and which are rather unlike $a$ priori mechanisms or traditional rational structures, are of primary importance. In pre-Modern philosophy, habit was often equated to experience, and in everyday language we say people are experienced when they are skilled and have accumulated a history of doing. Thus, along empiricist lines, experience is given primacy. The subject, as Dewey (1934) summed up, again mixing ideas from both schools, "brings with it through its own structure, native and acquired, forces that play a part 
in the interaction." It "acts as well as undergoes, and its undergoings are not impressions stamped upon an inert wax" (246), so that, to re-quote, perception is "an act of the going-out ... in order to receive" (53). With endless minute variations and combinations of action, and with particularities of individual subjects and objects encountered, possibilities of action are unlimited in number. However, they are not unbounded in scope. Fingers cannot spin like drills: the subject enters each encounter already endowed with certain potentialities and consequently cannot enact any pattern whatever.

Thus Dewey-again, in company with recent enactivists-rejected the empiricist notion that the subject waits "passive and inert for something to impress itself upon it from without" (1920, 86). As Noë (2004) put it, "perception cannot be represented in terms of merely passive, and internal, processes" (11) since it is constituted through outward action. At the same time, Dewey's and enactivist views challenge the position that subjects "project" perspectives outwards, as if onto an empty screen. We cannot perceive or even think whatever we want because we cannot do whatever we want. Hence while the hand projects itself into objects in the sense of reaching out and pushing into them, it does not make things completely in its own image. In projecting out, it meets the countervailing press of objects and therewith things limiting its actions and positions adopted. So whereas one can roll bottles between one's palms, the same action and hence same experience is impossible with cinderblocks. In this instance, therefore, it is a misnomer to say that what appears in experience is merely subjective, and the same, as will soon be seen, applies elsewhere. It is a misnomer because the possibilities of action delimiting particular experiences are not merely conditioned upon the subject, but also upon objects encountered, and the experience is largely constituted through actions in the world.

Seen accordingly, perceived qualities are qualities of interactions that occur in the world, as opposed to mere subjective representations of it (Dewey, 1925, 259; O'Regan and Noë, 2001, 960). Conceptually and phenomenologically, glassy smoothness is a property of the earlier mentioned bottle; yet in the current context it is inseparable from the hand's movements, save analytically. The property is inseparable because it is a consequence undergone, as Dewey (1934) would say (e.g., 44), in the course of an interaction - a consequence undergone when fingertips sweep over a surface that does not bite flesh. "We speak of perception and its object," Dewey remarked. "But perception and its object are built up and completed in one and the same continuing operation" (177).

Here one perhaps wants to plead that the bottle really is smooth, and not just when touched-we can see its smoothness, for example. True enough. 
Yet this is still to say it really is smooth within the context of particular interactions - or, to put it another way, that the smoothness is an effect of certain manipulations, and the effect is real. This is even so when the bottle meets the eye: the cornea bends light reflected from the bottle; the lens modifies its path further by adjusting to bring the bottle into focus; and these modifications are manipulations. Dewey (1920) made this point when he wrote that, while an astronomer cannot manipulate "stars themselves, he can at least by lens and prism change their light as it reaches the earth; he can lay traps for discovering changes [and therewith properties] that would otherwise escape notice" (113). Some might object that such modifications are trivial. Dewey (1934) would agree. He would add, however, that when we see the bottle, "[i]t is not just the visual apparatus" that becomes active, "but the whole organism" (122). Though researchers isolate "the optical apparatus ... in anatomical dissection, it never functions in isolation. It operates in connection with the hand in reaching for things and in exploring their surface, in guiding manipulation of things, in directing locomotion" (100). The sight of a brimming beer cooler invites outstretched arms, grasping, twisting of caps, opening of mouths, tilting heads, gulping and more, all of which characterizes the experience. It is true we sometimes look without grabbing. Yet it is also true that we spend most of our waking life handling and ambulating, which means coordinating actions around objects and settings; and true, moreover, that our eyes participate in most of this.

For such reasons, the enactivist position, along with Dewey's, suggests visual experience, like the earlier examples of tactile perception, is constituted through action. As Myin and Degenaar (2014) aptly explained:

Seeing a scene or an object is, in the sensorimotor approach, comparable to feeling a surface or object, where the experience is of the whole surface or object, despite the fact that momentary tactile stimulation is limited to the fingertips making contact only at particular places.

$[\ldots]$

For example, tactile feelings of hardness or softness are determined by particular patterns of experiences one has when engaging in such activities as squishing a sponge or pushing a brick wall. Similarly, that experiences of seeing differ as a class from experiences of hearing is due, according to the sensorimotor theory, to patterns of sensorimotor contingencies specific to vision and audition, such as that in seeing, but not in hearing, stimulation from a particular source stops when one turns one's head sideways, or closes one's eyes (91). 
Or as Noë (2004) summarized:

Like touch, vision is active. ... You and your eyes move around the scene the way you move your hands around the bottle. As in touch, the content of visual experience is not given all at once. We gain content by looking around just as we gain tactile content by moving our hands. You enact your perceptual content, through the activity of skillful looking (73)

Enactivists accordingly have maintained that visual perception, along with other modalities, "is constituted by the exercise of a range of sensorimotor skills" (Noë, 2004, 90), a claim supported with sensory substitution devices or experiments involving inverting glasses. With Paul Bach-y-Rita's (e.g., 1983, 1984; and Kercel, 2002) tactile-vision substitution system, as Noë (2004) explained, a head-mounted camera delivers stimulation via electrical current on the tongue or vibrations on skin. Individuals who actively explore their surroundings can, with time, come to grasp objects, identify their positions and numbers-in short, develop an analogue to vision. Experiments with glasses that invert the image hitting the retina suggest a similar point, according to Myin and Degenaar (2014), who summarized a number of studies showing that 1) people wearing such glasses see normally after five or six days, but that 2) adaptation is limited when head movement is restricted, highlighting the centrality of action and exploration in perception.

This does not obviate the fact that we sometimes look without overtly acting, but it does show that eyes-like hands-are vehicles for action, even if we happen to temporarily be sedentary, and suggests that we learn to perceive through acting. For Dewey (1934), moreover, it indicates that when the eyes are not involved in overt action, seeing is still "an affair of readiness on the part of motor equipment" (98). Thus when we see hallways or contours of bottles, we see spaces for movements or things we can handle. When we see shape and line, we see "ways in which things act upon one another and upon us; the ways in which, when objects act together, they reinforce and interfere" (100-101). Seeing entails perceiving what sorts of conduct our surroundings allow and disallow, as Dewey, with others such as J.J. Gibson (1979), suggested; and when we act, as the beer drinking example illustrates, a global assembly of sensitivities and capacities synchronize. On such a basis, Dewey maintained that "[n]othing is perceived" unless capacities "work in relation with one another" (175). Looking motivates touching or the reverse, or leads us to crane our head to hear, just as a repulsive odor makes us withdraw and so on. Our eyes and other modalities accordingly work in concert with motor capacities, as when a siren turns our head; or limbs collaboratively work pedals and 
a steering wheel to keep a car on the road seen ahead. When counting change, perusing magazines, typing and so on, "[m]otor and sensory structure form a single apparatus and effect a single function" (255). If an object stimulates only one organ, say, the eye, then "experience is thin and poor." However, "[w] hen the tendency to turn the eyes and head is absorbed into a multitude of other impulses and it and they become members of a single act," then "perception"-as opposed to "some specialized reaction"—-occurs" (256; emphasis added).

This picture of perception, which is also emphasized by Noë (2004), who wrote that "perception is a mode of activity on the part of the whole animal" (111), counters some putative cases of perceptual breakdown. Some reporters, for example, discussing research (see Zampini and Spence, 2004) showing that chips seem extra crispy when people hear crackling, have intimated that perception is untrustworthy. The problem, however, is that this conclusion fails to recognize that a food is crispy not solely because it fragments easily, but also because it has a certain a look, sound and manner of mobilizing the jaw and tongue - an overall way of synchronizing sensitivities and actions. Indeed, it is actually when capacities fail to coordinate into joint action by synchronizing around things that perception tends to fail.

As a case in point, Merleau-Ponty (1945) cited Aristotle's observation (see Dreams 46ob20) that one object feels like two when placed between crossed fingertips. Here, wrote Merleau-Ponty, "the synthesis of [...] tactile perceptions in one single object is impossible." It is because "the crossing of the fingers, being a movement which has to be imposed on them," interferes with their "motor possibilities," so that "the right face of the middle finger and the left face of the index cannot combine in joint exploration of the object" (205; emphasis added). Other perceptual illusions are similar. Consider the McGurk effect: the finding that dubbing the sound /ba/ onto lip movements for /ga/ results in most people hearing /da/ (McGurk and MacDonald, 1976). In this instance, subjects confront conflicting stimuli that pull sensitivities and capacities out of synchrony. Seen thus, the McGurk effect is not a consequence of something being wrong with subjects, but something being amiss in the situation in which they are placed. Furthermore, if we start with the assumption that perception is intermodal, which is affirmed by Dewey, Merleau-Ponty and at least hinted at by enactivists, we cannot even conclude that subjects misperceive the sound, for on this assumption, the isolated ear is not the arbiter of what they ought to hear.

Something similar, albeit more emphatic, can be said of Dawkins's example of timbre. The notion that we are deceived when we perceive the brassy sound of a trumpet rather than the separate harmonics follows only because Dawkins 
stipulates without justifying the basis that an accurate way to perceive is to have the soundscape teased apart into fragments. Dewey, by contrast, suggested that things only have properties in relation to one another and that humans are part of the relation, whether in the case of first hand inquiry or scientific investigation; he maintained further that action produces the specific phenomena registered. For this reason and ones to be elaborated upon, it makes no more sense to claim we are deceived when perceiving brassy timbres than it does to claim we are when registering the smoothness of a bottle we are handling or indeed detecting separate harmonics with technical instruments. All these phenomena result from specific action-scenarios. If judged according to specific scenarios generating them, there is no basis for concluding we are duped when we register them.

\section{v Dewey's Theory of Embodied Cognition}

Dewey's theory of perception, along enactivist lines, has at its basis skilled engagement with the world, a point emphasized when he said experience is art, and art the skill of the pilot, carpenter and so on (see Dewey, 1925, 354). This relates to his understanding of cognition, which he did not view as fundamentally distinct from perception. "To maintain, to expand, adequate function is [the] business" of life, wrote Dewey $(1908,48)$; and "the business of organic adaptation involved in all knowing [is] to make a certain difference in reality" (47). Living and knowing both involve "co-operative and readjusted changes in the cosmic medium" (p. 48; cf. Thompson, 2007, 128).

Here Dewey's use of "cosmic" corresponds roughly to the ancient Greek word kosmos, which might be translated as "orderly system," and his statement expressed what physicists of his day were coming to realize: that illuminating a system so that it can be seen and known actually disturbs the system. In quantum physics this is emphatically so, for as Dewey (1929) noted, at least one photon of light "is required to make, say, an electron visible," and the collision between the two "displaces to some extent the object observed" (204). The lesson Dewey drew is that knowing - as a variety of experience - is a "kind of interaction that goes on within the world" (204-205), so that "[w] hat is known is [...] a product in which the act of observation," which is an act of rearrangement, "plays a necessary role" (204).

In this regard, quantum mechanics is almost commonsensical, for we frequently observe things by changing or manipulating them. When "trying to make out the nature of a confused and unfamiliar object," wrote Dewey (1929), we "turn it over, bring it into a better light, rattle and shake it, thump, push 
and press it" (87). Or if we cannot directly jostle it, we "deliberately alter the conditions under which we observe [it]" (84). Either way we "make changes which will elicit some previously unperceived qualities" (87). Thus inquiringlike perceiving - is an act of going out in order to receive. This means, on the one hand, that we garner observations from the world in return for acting upon it; and, on the other, that what we receive is of little worth when we fail to act within certain limits. Using ill-suited instruments, ignoring constraints of materials and banging about randomly will elicit observable effects, but the relationships between them will likely appear haphazard and meaningless.

This reiterates Dewey's rationale for characterizing "knowing" in terms of art or skilled doing - a characterization that obviously mirrors his and enactive accounts of perception. Carpentry is an art, and someone is an artisan, Dewey (1920) explained, only if "he notes things not just as objects in themselves, but with reference to what he wants to do to them and with them; to the end he has in mind" (114-115). The end, if it is to be achieved, limits what materials can be used, and the materials limit how the carpenter can deploy his skills. Consequently he acquires the habit of seeing things in terms of possible actions and uses:

Fitness to effect certain special changes that he wishes to see accomplished is what concerns him in [...the materials] he observes. His attention is directed to the changes they undergo and the changes they make other things undergo so that he may select that combination of changes which will yield him his desired result (115).

So when the carpenter calls pine "a softwood," he indicates pine is easy to sand and hammer nails into, but also easy to scratch and thus not appropriate for kitchen floors. From his standpoint, things and their properties "are what they can do and what can be done with them," and "[i]t is only by [...] active manipulation of things in order to realize his purpose that he discovers what the properties of things are" (115).

In these various examples properties appear not only in consequence of what observers do, but in consequence of "changes [things] make other things undergo" (Dewey 1920, 115). Dewey's point, therefore, is one hinted at in Peirce's pragmatic maxim (see Peirce, 1878,293 ) and emphasized by other leading thinkers of his day, for example, Nietzsche (1967 [c. 1885-1886], §557) and Merleau-Ponty $(1945,1947)$ : that properties are effects of relationships. Dewey's analysis suggests, among other things, that the distinction between so-called "secondary" properties such as color and "primary" ones such as length and mass is misleading. It is misleading, to extrapolate just a little 
beyond Dewey who in fact drew insights from Einstein's theories of relativity (see Dewey, 1929, chapters 5,6), because an object's color, length and mass all depend on its velocity relative to the point of observation. As with color, therefore, length and mass - mass here understood as resistance to accelerationare not determinable properties of isolated entities, but effects of relationships between them (see Crippen, 2010 497).

With something like this in mind, Dewey (1925) insisted that perceived qualities are not mere representations "in" the sensate organism, but rather "qualities [or effects] of interactions in which both extra-organic things and organisms partake" (259), more or less anticipating O'Regan and Noë's (2001, 960) thesis that qualitative aspects are features of our activity. Thus, as Dewey (1908) elaborated, qualities such as "red, or far and near or hard and soft, or big and little" are undeniably relative (45). They are so, however, in the literal sense that they involve "a relation between organism and environment," which by pushing back limits what the organism can do, and this is no basis for "proclamations of the agnostic 'relativity' of knowledge"; it is "an argument for the ultimately practical value of distinctions." Distinctions "are differences made in what things would have been without organic behavior-differences made not by 'consciousness' or 'mind,' but by the organism as the active center of a system of activities" (45).

The combination of this system of activities and the active organism can be thought of as a situation. Situations in Dewey's sense of metaphysically broader, so that living in Cairo, with all its physical and cultural affordances and restraints is a situation, whereas a specific night out on the town is an experience (Chudoba, 2017). Situations can be more local as well, but whatever the case, situations provide context in which things can show up meaningfully (see Dewey, 1938, esp. 66-67). If we are in a kitchen, our situation includes us, and likely such things as walls, furniture, sink and stove, and perhaps a cat sniffing at our feet. These constituents delineate possibilities of action and organization. If we remove, say, the table, we can traverse the space it occupied, but cannot lean our elbows where we once did; nor can the tablecloth continue to rest 80 centimeters above the floor. Limits also vary depending on the active center. The cat is one such center; a person another. Because the two come to the kitchen endowed with different capacities and limitations, they face, as the expression goes, different situations. We can imagine, therefore, that they perceive their situations differently, yet this is here equivalent to "perceiving objectively different situations." It is equivalent because the cat and person face objectively different constraints - they, like the table and sink, are able to do different things. It is no mere variation in mental outlook that differentiates the perceptual experience of sipping a glass of milk from that of lapping from a dish while on all fours. It is a difference in action. If the person 
caresses a table leg while the cat scratches it, different actions are performed, and different actions realize different properties as effects. Easy sweeps of fingertips realize smoothness of lacquered wood, while digging claws realize its sinewy toughness, all of which is to repeat: perception and cognition are preeminently a matter of acting and altering worldly arrangements, as opposed to merely representing them.

Dawkins's views on mind imply a view, which I take to be fairly common in scientific circles and also among psychology and philosophy professors. Put crudely, the view is that the human mind is feeble. Also implied is that scientists know best, which translates to non-scientific folk are mostly duped. Without discounting science, which is after all utilized in the work of Dewey and enactivists and to that extent also in this article, I will conclude by detailing how many of Dawkins's observations, along with Hoffman's, if read from a Deweyan perspective, affirm a position contrary to the one intended.

Dawkins (2006), it will be remembered, stated that there is "simulation software in the brain" (89) and that "[w] hat we see ... is not the unvarnished real world but a model of [it]" (371) built "inside our head" (361). Hoffman (2009, 2011; and Prakash, 2014), without pushing the idea of simulation software, argued that the perceptual system is geared to facilitating interface with the world, not producing veridical representations. Like so many others, today and through history, both cited perceived hues as an example, with Dawkins (2006) calling them "internal labels" (372) having "no intrinsic connection with lights of particular wavelengths" (373), which he takes as the genuine reality. In Dawkins's words, perceived hues are "tools" used to construct a "model of external reality" that mark "important distinctions in the outside world" (373). An animal's "world-representing software" is adapted to its particular "way of life," and Dawkins accordingly reasoned "that bats may 'see' colour with their ears." After all, "[t]he world-model that a bat needs ... must surely be similar to the model that a swallow needs" (372). Bats may accordingly use hues "as internal labels for some useful aspect of echoes," so that "the nature of the model is governed by how it is to be used rather than by the sensory modality involved" (372).

I take roughly half of this speculative account to be correct. Enactivist theories and specifically sensory substitution devices indeed affirm that our experience of the world is governed in significant degree by action in it, so that even conventionally non-visual sensory modalities can become visual in practice, in line with what Dawkins said, albeit without anything approaching the 
experience of hues. Yet this also suggests - and this is the point Dawkins and Hoffman missed-that perceptual experience is not merely constructed in the head, but built through enacted interrelations. To re-quote Dewey (1925), perceived qualities are conceived poorly if reduced to internal representations since they are also "qualities of interactions in which both extra-organic things and organisms partake" (259). This is obviously so for tactile qualities such as smoothness, yet no less so for other kinds of properties. Enactivist accounts attest to this. Also attesting to this is the notion that interrelationships are epistemically and ontologically primary. That is, they are where things and events with specifiable, perceivable and knowable qualities initially and actually exist. Color, length and mass, all depend on velocity relative to the point of observation, which is to say, they are effects that show up only in the context of interrelations. Consequently before the perceiver arrives, properties are already effects; and if effects count as "real," and are not arbitrarily deemed "unreal" merely because a perceiver participates in the interrelations, then there is no reason to grant them less reality than wavelengths of light, which also show up as particular wavelengths as an outcome of specific relations and indeed actions, for instance, individuals selecting and setting up detecting instruments that introduce changes to the phenomena observed.

Consider another example of Dawkins's (2006) skepticism. In this passage he informed readers that:

Science has taught us, against all evolved intuition, that apparently solid things like [...] rocks are really composed almost entirely of empty space. [...] So why do rocks look and feel solid and hard and impenetrable? [...] Our brains have evolved to help our bodies find their way around the world on the scale at which those bodies operate. We never evolved to navigate the world of atoms. If we had, our brains probably would perceive rocks as full of empty space. Rocks feel hard and impenetrable to our hands because our hands can't penetrate them. The reason they can't penetrate them is unconnected with the sizes and separations of the particles that constitute matter. Instead, it has to do with the force fields that are associated with those widely spaced particles in 'solid' matter. It is useful for our brains to construct notions like solidity and impenetrability, because such notions help us to navigate our bodies through [the] world... (368).

From Dewey's standpoint, this mostly reduces to the claim that perception reflects the situation or relationship we objectively find ourselves acting in, and if we were to find ourselves in another, our perception would reflect it. 
In relation to our bodies, rocks are, objectively speaking, impenetrable. So in this instance perception is not duped. Also misleading is Dawkins's suggestion that we perceive rocks as solid primarily because of "evolved intuition." This is an overuse of theoretical machinery, specifically in the form of Darwinism, and also an overstatement on the degree to which evolved and in this sense hardwired representations determine our view of things. After all, if the rules of physics suddenly allow hands to pass through rocks, we will perceive this. Actions, in short, trump evolved intuitions and the like. Indeed, it is largely by acting on materials in the world - by altering the situations in which they are observed - that scientists have reached the conclusion that material objects are mostly composed of space, which does not, in any case, contradict our experience of their solidity for reasons to be discussed.

The error in Dawkins's interpretation is reminiscent of that of commentators teaching introductory physics, who sometimes charge that Democritus misrepresented reality by claiming atoms are indivisible. In making this claim, they neglect the fact that atomas meant "indivisible" and that it was modernera scientists who misapplied the term when they initially but wrongly concluded that what they called "atoms" fit this description. Dawkins similarly erred when he insinuated we mistakenly call objects "solid" and "impenetrable," for we rarely use these terms to describe atomic arrangements. Rather, we use them to indicate what we can do with things and they to us-something Dawkins conceded, without following the point to its pragmatic conclusion. Solidly built chairs bear our weight. Impenetrably solid fogs impede vision and movement. Unlike liquid or gas, we can handle solid ice, walk on it or risk falling through it. George Lakoff and Mark Johnson $(1980,1999)$ have made comparable points throughout their work, as has Merleau-Ponty (1945), and none of these linguistic uses of the word "solid" contradicts claims about or even says anything about the molecular structure of matter.

As with Dawkins, Dewey (e.g., 1920, 84-86), like James before him (see Crippen, 2010, 2011), acknowledged a debt to evolutionary biology. Like Dawkins (2006), moreover, who suggested that concepts are tools for adapting to the world (368-372) and that we do not see "the unvarnished real world" (371), Dewey regarded concepts as instruments. Consequently Dewey (1920) agreed they are not "bare transcript[s] or duplicate[s] of some finished [...] arrangement pre-existing in nature" (154), for copying reality is not the chief function of instruments. Rather, instruments help us negotiate realities, and also change them, so that there is no "finished arrangement" to represent. Dawkins emphasized some of this. Yet he also stressed that we build models of the world "inside our head" (361) and failed to convey, as Dewey (1920) stated, that an instrumental view of classification "does not commit us to the notion that 
classes are $[\ldots]$ purely mental" or "merely nominal" (154). It does not because our conceptual classes are realized in "objective action" (154).

To sum up, Dewey would agree adaptability is key, but add there is no preexisting truth to represent, a point Hoffman acknowledged more readily than Dawkins, citing quantum mechanics as a case in point (see Hoffman and Prakash, 2014). However, Hoffman's framing of the discussion is skeptical—and arguably more so than Dawkins's - insofar as he hinted that we must therefore abandon all claims about having genuine access to reality. Hoffman's discussions are also confused in that he suggested there is no pre-existing truth while citing standard examples of objective reality, for example, wavelengths of light in order to show that our perception is adaptive but not accurate. Hoffman (2009) argued that perceptual theories should be reoriented from "categories of the objective world" to "categories of an organism's perceptual world" (153), unaware these can be the same, as the earlier example of the cat versus human illustrate. Here the cat and human live in objectively different worlds because they can do different things, which also leads them to have different perceptual worlds. Hoffman also said that adaptability trumps truth (151), and challenged enactive theories, seemingly unaware that truth and fitness are typically not in conflict when judged from an action-based standpoint.

The carpenter's general distinction, for example, between hard and softwood is realized in how he generally works and builds with lumber. Very literally, therefore, the distinction is based in human constructions. Yet we do not designate houses and other constructed entities as figments of imagination, so Dewey (1925) warned against rejecting conceptual distinctions as such simply because they reflect worldly arrangements we help build (see 181-191). Like artists, elaborated Dewey, we confer "upon things traits ... which did not previously belong to them" (381). Complaints that this makes knowledge a "perversion" reflects "a confusion of tenses. Knowledge is not a distortion ... which confers upon its subject-matter traits which do not belong to it, but is an act which confers upon non-cognitive material traits which did not belong to it" (381). Changes resulting from the general uses to which the carpenter puts hard and softwoods are objectively realized in schemes of worldly activity.

With action as a starting point, classical pragmatists and especially Dewey thus offered theories of mind that challenge the notion, propagated by thinkers ranging from Descartes and Hume to Dawkins and Hoffman, that the individual perceiver and thinker does not have genuine access to reality. They did so by suggesting, first, that much of what we call cognition goes on outside the head; second, that the primary job of perception and cognition is not to represent the world, thereby downplaying the importance of representations, arguing instead that the measure is usefulness to life; and, third, that things 
only have properties in relation to one another and that humans are part of the relation, making it nonsensical to conclude that we misperceive when we register the solidity of the chair on which we are sitting, or the brassy timbre of a trumpet.

Classical pragmatists also challenged traditional epistemologies by suggesting there is rarely one version of reality to which an idea or percept ought to correspond (see James, 1878, 921-922). For example, observable spatial relations between planets accord equally well with the thesis that the solar system is heliocentric and the contrary thesis that the Sun orbits the Earth, and the other planets the Sun, with background stars annually undulating lockstep (see Crippen, 2010, 485-486, 501; Crippen, 2015, 87-89). However, very few today accept the latter view, and for good reason, namely, that fit between facts and representations - whether in the form of scientific models or mental entities - is rarely if ever adequate grounds for accepting a theory, as James (1907), among others, pointed out. Other bases such as elegance, economy and consistency with other accepted beliefs-in short, non-evidential criteria that enhance workability - have long been employed in the sciences and elsewhere, with James accordingly subtitling his 1907 Pragmatism, "a New Name for Some Old Ways of Thinking." The primacy of workability, which of course includes fit with data but only among much else, emphasizes actions and their consequences. It also again draws attention to the wrongheadedness of concluding that we are in error when perceiving a brassy timbre of a trumpet, as opposed to separate harmonic tones, or when we perceive rocks as solid. More than one experience fits brute facts and many are workable in different contexts and do not even much of the time contradict one another.

The scientifically informed account of perception and cognition offered by classical pragmatists and especially Dewey accordingly helps overcome the skepticism that characterizes certain scientific visions, along with Modern era accounts of mind that remain in play today. Dewey, with James and others, took unequivocal cues from the physical and biological sciences, while also anticipating recent turns in cognitive science; and he and his philosophical confederates delivered scientifically informed pragmatic frameworks within which a compelling case can be made that the individual perceiver and thinker is not continually duped.

\section{References}

Aristotle. 1941. On Dreams. J.I. Beare, trans, in The Basic Works of Aristotle, ed. Richard McKeon (New York: Random House), pp. 618-625. 
Bach-y-Rita, Paul. 1983. "Tactile Vision Substitution: Past and future," International Journal of Neuroscience 19: 29-36.

Bach-y-Rita, Paul. 1984. "The Relationship between Motor Processes and Cognition in Tactile Vision Substitution," in Cognition and Motor Processes, eds. A.F. Sanders and W. Prinz (New York: Springer), pp. 150-159.

Bach-y-Rita, Paul and Kercel, Stephen. 2002. "Sensory Substitution and Augmentation: Incorporating Humans-in-the-Loop" Intellectica 2: 287-297.

Chudoba, E. 2017. "What Controls and What Is Controlled? Deweyan Aesthetic Experience and Shusterman's Somatic Experience." Contemporary Pragmatism 14, page range.

Crippen, Matthew. 2010. "William James on Belief: Turning Darwinism against Empiricistic Skepticism,” Transactions of the Charles S. Peirce Society, 46: 477-502.

Crippen, Matthew. 2011. "William James and his Darwinian Defense of Freewill." In 150 Years of Evolution: Darwin's Impact on Contemporary Thought and Culture, ed. Mark Wheeler (San Diego: San Diego State University Press), pp. 68-89.

Crippen, Matthew. 2014. "Body Phenomenology, Somaesthetics and Nietzschean Themes in Medieval Art," Pragmatism Today 5: 40-45.

Crippen, Matthew. 2015. "Pictures, Experiential Learning and Phenomenology," in Visual Learning, vol. 5: Saying by Showing, Showing by Saying-Pictures, Parables, Paradoxes, eds. András Benedek and Kristof Nyiri (New York: Peter Lang), pp. 83-90.

Crippen, Matthew. 2016a. "Dewey, Enactivism and Greek Thought," in Pragmatism and Embodied Cognitive Science: From Bodily Interaction to Symbolic Articulation, eds. Roman Madzia and Matthias Jung (Boston: De Gruyter), pp. 229-246.

Crippen, Matthew. 2016b. "Dewey on Arts, Sciences and Greek Philosophy," in Visual Learning: Time, Truth, Tradition, András Benedek and Ágnes Veszelszki (New York: Peter Lang), 153-159.

Daugman, John. 2001. "Brain Metaphor and Brain Theory," in Philosophy and the Neurosciences: A Reader, eds. William Bechtel, Pete Mandik, Jennifer Mundale and Robert Stufflebeam (Oxford: Blackwell Publishers), pp. 23-36.

Dewey, John. 1908. "The Practical Character of Reality," in Philosophy and civilization [1931] (New York: Minton, Balch and Company), pp. 35-56.

Dewey, John. 1920. Reconstruction in Philosophy (New York: Henry Holt and Company). Dewey, John. 1925. Experience and Nature (Chicago: Open Court Publishing Company). Dewey, John. 1929. The Quest for Certainty (New York: Minton, Balch and Company).

Dewey, John. 1934. Art as Experience (New York: Minton, Balch and Company).

Dreyfus, Hubert. 2003. Existential Phenomenology and the Brave New World of the Matrix, The Harvard review of Philosophy, 11: 18-31.

Galton, Francis. 1883. Inquiries into Human Faculty (New York: Macmillan).

Gibson, J.J. 1979. The Ecological Approach to Visual Perception (Boston: HoughtonMifflin). 
Hoffman, Donald. 2009. "The Interface Theory of Perception: Natural Selection Drives True Perception to Swift Extinction," in Object Categorization: Computer and Human Vision Perspectives, eds. Sven Dickinson, Aleš Leonardis, Bernt Schiele and Michael J. Tarr (New York: Cambridge University Press), 148-165.

Hoffman, Donald. 2011. "The Construction of Visual Reality", in Hallucination: Research and Practice, eds Jan Dirk Blom and Iris Sommer (New York: Springer), pp. 7-15.

Hoffman, Donald and Prakash, Chetan. 2014. Objects of consciousness, Frontiers in Psychology, 17: n.p.

Hutto, Daniel and Myin, Erik. 2013. Radicalizing Enactivism Basic Minds without Content (Cambridge, MA: Mit Press).

James, William. 1907/1987. Pragmatism, in William James: Writings 1902-1910, ed. Bruce Kuklick (New York: Library of America), pp. 479-624.

Lakoff, George and Johnson, Mark 1980. Metaphors We Live By (University of Chicago Press).

Lakoff, George and Johnson, Mark 1999. Philosophy in the Flesh (New York: Basic Books).

Merleau-Ponty, Maurice. 1945. Phenomenology of perception, trans. Colin Smith [1962] (New York: Routledge and Kegan Paul).

Myin, Erik and Degenaar, Jan. 2014. "Enactive Vision," in The Routledge Handbook of Embodied Cognition, ed. Lawrence Shapiro (New York: Routledge), pp. 90-98.

Nietzsche, Friedrich. 1968. The Will To Power [a posthumously published collection of Nietzsche's working notes], eds. and trans. Walter Kaufmann and R.J. Hollingdale (New York: Vintage Books).

Nyíri, Kristof. 2014. Meaning and Motoricity: Essays on Image and Time (New York: Peter Lang).

Noë, Alva. 2004. Action in Perception (Cambridge, MA: MIT Press).

Noë, Alva. 2009. Out of our heads: Why You Are not Your Brain, and other Lessons from the Biology of Consciousness (New York: Hill and Wang).

O'Regan, Kevin and Noë, Alva. 2001. A Sensorimotor Account of Vision and Visual Consciousness, Behavior and Brain Sciences 24: 939-973.

Peirce, C.S. 1878/1982. "How to Make our Ideas Clear," in Writings of Charles S. Peirce: A ChronologicalEdition, Vol. 3, ed. Christian Kloesel (Bloomington: Indiana University Press), pp. 257-276.

Rockwell, Teed. 2005. Neither Brain nor Ghost: A Nondualist Alternative to the MindBrain Identity Theory (Cambridge, MA: MIT Press).

Rockwell, Teed. 2014. "How Computational Neuroscience Revealed that the Pragmatists Were Right," in Neuroscience, Neurophilosophy and Pragmatism: Brains at Work in the World, eds. Tibor Solymosi and John Shook (New York: Palgrave Macmillan), pp. $57-70$.

Schulkin, Jay. 2004. Bodily Sensibility: Intelligent Action (New York: Oxford University Press). 
Schulkin, Jay. 2016. "Foraging for Coherence in Neuroscience: A Pragmatist Orientation," Contemporary Pragmatism 13: 1-28.

Solymosi, Tibor and Shook, John. 2013. "Neuropragmatism: A Neurophilosophical Manifesto." The European Journal of Pragmatism and American Philosophy, 5: 212-234.

Thompson, Evan 2007. Mind in life: Biology, Phenomenology, and the Sciences of Mind. (Cambridge, MA: Harvard University Press).

Titchener Edward. 1909. Lectures on the Experimental Psychology of the ThoughtProcesses (New York: Macmillan).

Washburn, Margaret, 1916. Movement and Mental Imagery: Outlines of a Motor Theory of the Complexer Mental Processes (Boston: Houghton).

Zampini, M. and Spence, C. 2004. The Role of Auditory Cues in Modulating the Perceived Crispness and Staleness of Potato Chips. Journal of Sensory Studies 19: $347-363$. 